\title{
Cidadania, Participação Popular e Saúde na Visão dos Profissionais do Setor: Um Estudo de Caso na Rede Pública de Serviços ${ }^{1}$
}

\author{
Citizenship, Community Participation, and Health As Seen by Health \\ Care Professionals: A Case Study in Public Health Services
}

\begin{abstract}
Maria Lúcia M. Bosi²
BOSI, M. L. M. Citizenship, Community Participation, and Health As Seen by Health Care Professionals: A Case Study in Public Health Services. Cad. Saúde Públ., Rio de faneiro, 10 (4): 446-456, Oct/Dec, 1994.

This paper deals with the subject of citizenship and people's participation in the health area through an analysis of ideas pertaining to a specific group: health care professionals working in Basic Health Care Clinics in the 3.1 Programatic Area of the City of Rio de Faneiro (Brazil). The article analyzes their views on the subject and presents them in light of health-related legislation in the Brazilian constitution. It also analyzes the professionals' role vis-à-vis users in raising community awareness that health care is one of their basic rights.

Field data from qualitative social research methodology showed a significant heterogeneity in the professionals' conceptions, dividing them into two groups: those belonging to teaching institutions and those working in institutions providing health care.

This analysis shows the strategic role that day-to-day relationships between professionals and the community can play in the social change process and the establishment of social rights. It also discusses the viability of this process in view of the discovery of the subjective involvement of the health professionals who promote this process.
\end{abstract}

Key words: Health Professionals; Health Care; Citizenship; Community Participation

\section{INTRODUÇÃO}

A Declaração de Direitos que compõe a atual Constituição Brasileira a caracteriza como um dos mais avançados textos constitucionais do mundo, particularmente no que se refere ao conjunto de direitos sociais que promulga e sobretudo quanto aos direitos no campo da Saúde.

Sob o lema "Saúde direito de todos e deverdo Estado" Constituição Brasileira (1988), revela-se um importante deslocamento teórico

\footnotetext{
${ }^{1}$ Esta pesquisa foi desenvolvida com recursos provenientes da Fundação de Amparo à Pesquisa do Estado do Rio de Faneiro.

${ }^{2}$ Núcleo de Estudos de Saúde Coletiva da Universidade

Federal do Rio de Faneiro. Rua dos Coelhos, 450,

$1^{\circ}$ andar, Recife, PE, 50070-550, Brasil.
}

conceitual do tema "Saúde" de um campo estritamente biológico para o campo político e histórico da construção dos direitos.

Contudo, esta nova abordagem por si só não é capaz de materializar em práticas as conquistas legais que representa; no caso brasileiro, há um descompasso evidente entre os dois níveis, sendo oportuno lembrarmos que "é função prática da linguagem dos direitos, a de emprestar força particular às reivindicações dos movimentos que demandam para si e para os outros satisfação de novas carências materiais e morais; ao mesmo tempo em que a torna enganadora e obscurece a diferença entre $o$ direito reivindicado e o direito reconhecido $e$ protegido" (Bobbio, 1992: 10).

No que tange ao processo de construção dos direitos à saúde, destacamos dois aspectos como fundamentais: o primeiro deles corresponde à 
formação de uma consciência sanitária, entendida no contexto deste estudo como " $a$ tomada de consciência de que a saúde é um direito da pessoa e um interesse da comunidade" Berlinguer (1978: 05); e o segundo aspecto, intrinsecamente ligado ao primeiro, situa a participação popular como mecanismo fundamental no referido processo.

Dentro do tema Cidadania e Saúde, a questão da participação popular não pode, portanto, ser negligenciada. Daí seu destaque dentro deste estudo, especialmente por se constituir também em direito garantido no texto constitucional, compondo uma das principais diretrizes do atual sistema de saúde.

Por outro lado, para que a relação dialética conscientização/participação se desenvolva, parece-nos estratégico, no caso do setor saúde, o espaço micro da prática participativa representado por relações cotidianas como as que se estabelecem nas Unidades de Serviço. O cotidiano enquanto experiência de vida torna-se fundamental à localização de elementos através dos quais os atores sociais constroem suas percepções referentes à vida social, ao mesmo tempo em que representa um espaço de luta, de exercício de poder, poder que aqui é entendido "não como um objeto natural, uma coisa", mas como "prática social".

A construção gradual de uma consciência sanitária alimenta-se de experiências vivenciadas na realidade cotidiana e, neste plano, as explicações macroestruturais não parecem dar conta da complexidade das relações e seus desdobramentos (sobretudo da esfera da subjetividade). Portanto, falar em construção da cidadania e em participação popular como exercício de direitos no campo da saúde, pede uma reflexão sobre estas noções tal como se apresentam na subjetividade que se associa à prática dos profissionais do setor.

O papel dos profissionais de saúde na relação cotidiana com os usuários da rede de serviços, longe de se revestir de um significado meramente técnico (assistencial) se inscreve numa prática pluridimensional, dentre as quais se destaca a dimensão política.

Contribuir para o desvendamento da sub- jetividade deste grupo foi o que objetivamos, a partir da análise da questão da cidadania, participação popular e saúde no interior desta relação.

\section{PERCURSO METODOLÓGICO}

A natureza do nosso objeto impôs a metodologia qualitativa como concepção teórica de abordagem, na medida em que a entendemos como "aquela capaz de incorporar a questão do significado e da intencionalidade como inerentes aos atos, às relações e às estruturas sociais" (Minayo, 1992: 10).

Nosso estudo desenvolveu-se junto aos profissionais que atuam nas Unidades de Saúde que integram a Área Programática 3.1 (AP-3.1) do Município do Rio de Janeiro. Esta área envolve a região da Ilha do Governador e Leopoldina, abrangendo um total de 38 bairros e 84 favelas - população que representa $14,5 \%$ da população total do Município do Rio de Janeiro, sendo a terceira área em densidade demográfica no Município (10.971 hab $/ \mathrm{km}^{2}$ ) (Carvalho, 1991).

Nosso espaço de observação correspondeu, portanto, às unidades públicas de serviços básicos, localizadas na área programática em que se insere a Universidade Federal do Rio de Janeiro (AP-3.1), o que significa dizer que trabalhamos com um universo de cinco unidades.

Inicialmente, pretendíamos desenvolver nosso estudo de caso tomando como base apenas uma unidade para a realização das entrevistas. Entretanto, este procedimento (adequado em outras situações) foi por nós descartado pelo fato de não estarmos lidando com um conjunto homogêneo, como constatamos na fase exploratória desta pesquisa.

A linha divisória mais importante foi dada pelo fato de se incluírem neste conjunto dois tipos de Unidades: as que denominamos "Unidades de Ensino" (Unidades ligadas a instituições formadoras) - Germano Sinval Faria (Ensp) e Vila do João (UFRJ), e as "Unidades Assistenciais" — as que não se vinculam tradi- 
cionalmente a Programas de Capacitação de Recursos Humanos em Saúde Pública (Centros Municipais de Saúde localizados nos bairros de Ramos, Penha e Ilha do Governador).

Nosso material (a subjetividade de um grupo social específico) parecia diferir bastante ao compararmos unidades ligadas a Núcleos de Ensino como por exemplo a Germano Sinval Faria (Ensp/Fiocruz) ou outras, como o Centro Municipal de Saúde Necker Pinto (Ilha) ou Américo Fontenele, já que os processos históricos de formação e consolidação das respectivas equipes e do modelo de atendimento não se reduzem uns aos outros de maneira mecânica. Na medida em que este material parece-nos bastante rico para a análise pretendida, consideramos a opção metodológica de distribuir as entrevistas pelo conjunto das Unidades como o procedimento mais adequado aos nossos objetivos.

Sendo fundamentalmente a dimensão subjetiva o nível em que se situa nosso objeto, o material básico com que trabalhamos foi o discurso dos agentes. Bakhtin, citado por Minayo (1992: 110), considera a palavra "o fenômeno ideológico por excelência" e define o "caráter histórico e social da fala como um campo de expressão das relações e das lutas sociais que ao mesmo tempo sofre os efeitos da luta e serve de instrumento e de material para a sua comunicação". É a partir da palavra que se pode, portanto, apreender o conteúdo simbólico das práticas.

No caso específico deste trabalho, falar em direito, cidadania, participação e controle social em saúde, conceitos fortemente vincu-lados ao processo de tomada de consciência da saúde como um direito implica no conhecimento do "conteúdo da consciência" — representações, idéias, pensamentos — dos sujeitos envolvidos. No que se refere à consciência sanitária, e considerando estratégico o espaço da assistência, nosso ponto de partida foi o estudo das manifestações desta consciência expressas sob forma de linguagem no discurso de profissionais do setor.

Partindo dessas premissas, realizamos nosso estudo junto aos técnicos das Unidades de Saúde já citadas. O grupo selecionado constitui-se por categorias profissionais de nível superior — "os profissionais de saúde" das Unidades.
$\mathrm{Na}$ seleção dos entrevistados, buscamos a "face" da equipe das unidades. Pudemos notar, a partir de levantamento quantitativo, que a categoria dos médicos somada à dos enfermeiros representava $64 \%$ do pessoal de nível superior, encontradas em todas as Unidades. A partir desta primeira constatação procuramos entrevistar aqueles profissionais com maior tempo de serviço e que em cada Unidade mantinham um contato mais efetivo com a população o que deduzimos por observação, além das informações de grade horária dos funcionários.

Já que partimos de uma perspectiva qualitativa, no que se refere a amostragem não se colocou para nós questões como "representatividade", "verificabilidade" ou "generalização" nos termos que estas questões, entre outras, se impõem à tradição quantitativa. Aqui nossa preocupação foi "menos com a generalização e mais com o aprofundamento e abrangência da compreensão" ... Um critério portanto não numérico. A amostra ideal sendo "aquela capaz de refletir a totalidade nas suas múltiplas dimensões" (Minayo, 1992: 102).

Dentre as técnicas disponíveis, optamos pela entrevista, elegendo dentre elas a não-diretiva por entendê-la como uma técnica que possibilitaria ao entrevistado discorrer sobre o tema em questão, a partir de uma lógica própria. Entretanto, optar por esta técnica não implica em destituí-la de problemas a começar pelo que se entende por "não-diretividade" (Thiollent, 1987).

Ainda assim e sem desconhecer as questões sócio-epistemológicas aí envolvidas, cuja complexidade não pode ser aqui analisada, adotamos a perspectiva de Michelat (1975), quando sugere a entrevista não-diretiva como uma técnica que oferece vantagens para apreensão do conteúdo simbólico permitindo ao entrevistado uma "atitude de exploração" na medida em que não estrutura completamente o campo de investigação. Por outro lado, talvez a ruptura com o referencial positivista, permitindo uma redefinição dos papéis de entrevistador e de entrevistado ofereça uma chance de superação das dificuldades colocadas por outras técnicas mais "fechadas" tais como entrevistas e questionários pré-estruturados. 


\section{CIDADANIA, PARTICIPAÇÃO POPULAR E SAÚDE: A CONCEPÇÃO DOS PROFISSIONAIS}

A análise do material obtido a partir das entrevistas levantou grande volume de informações que após sucessivas leituras e classificações, foram organizadas em torno do que se poderia considerar quatro grandes temas, a partir dos quais procuramos apreender nosso objeto:

1) O conceito de saúde.

2) A consciência sanitária.

3) O cotidiano da prática profissional.

4) A transformação do quadro atual.

Nossa hipótese inicial, relativa à distância existente entre vários aspectos da subjetividade dos profissionais das Unidades-Ensino se comparada a dos que pertencem às "UnidadesAssistenciais" pode então se confirmar, conforme veremos a seguir.

O Conceito de Saúde - No discurso dos profissionais que pertencem às Unidades-Ensino, o conceito de saúde é um conceito ampliado que considera, de modo claro, pelo menos três dimensões do fenômeno: a dimensão biológica, a social e a psicoafetiva.

A dimensão biológica aparece claramente na referência às doenças, à fisiologia, às patologias. A social, na forte referência aos determinantes sociais dos agravos à saúde da população e, finalmente, a afetiva na medida em que se constata uma forte valorização do componente simbólico e dos aspectos afetivos envolvidos no ato de curar e de sentir saudável:

- "Interferir no processo de doença significa interferir... no modo de viver e de ver a vida”. - "É necessário tratar a pessoa como um todo e não só a doença da pessoa”.

As representações deste segmento de profissionais, parecem ir ao encontro da noção de que “... a enfermidade física é apenas uma das numerosas manifestações de um desequilíbrio básico do organismo" (Capra, 1987: 127).

A formação recebida por estes profissionais, aliada à constante reflexão teórica presente no dia-a-dia da prática das Unidades Ensino, a nosso ver, é um dos elementos decisivos para a construção de uma visão oposta à "influência do paradigma cartesiano sobre o pensamento médico" que "levou os médicos a se concentrarem na máquina corporal e a negligenciarem os, aspectos psicológicos, sociais e ambientais da doença" (Capra, 1987: 137). Como pudemos levantar no momento das entrevistas, a totalidade dos entrevistados declarou ter concluído pelo menos um curso na área de saúde coletiva, a maioria afirmando que este fato "transformou totalmente sua visão profissional".

Quanto aos profissionais que atuam nas demais unidades, observa-se o predomínio da idéia do corpo como máquina, da dominância da dimensão biológica sobre as demais. Neste grupo, segundo constatamos, a influência do “modelo biomédico" (Capra, 1987), é mais intensa, ligando-se mais fortemente à idéia de intervenção:

- “(...) Ela estando em pleno estado de bem de saúde, sem nenhuma enfermidade, né?"

- “Bom, a pessoa gozar de perfeito bem-estar, né?

... De repente, não sentir nada. $A$ ausência de doença..."

O conceito de saúde da população usuária, segundo a percepção dos profissionais de saúde, também surgiu no material discursivo. $\mathrm{E}$ aqui as opiniões dos dois segmentos convergem para a idéia de que:

- “A concepção de saúde é muito imediatista, quer dizer, eles (a população) querem resolvero problema agora..."

- "Saúde aqui é muito assim: 'tá doendo, eu vou; não tá doendo, eu não vou', entende?"

E criticam a ausência de uma postura de prevenção:

\section{- “A preocupação deles é saber se eles podem trabalhar, ou se não podem".}

Foi interessante observar que ambos os grupos criticam esta postura "imediatista" e esta idéia da saúde com "ausência de dor". Entretanto, nenhum profissional questiona em seu 
depoimento, se há espaço para outras posturas (especialmente a preventiva) se expressarem na atual estrutura dos serviços.

No entanto, nos relatos sobre o cotidiano das Unidades, bem como em outros momentos analisados adiante, a realidade material em que se baseiam as posturas desta população parecem fornecer elementos para uma compreensão mais profunda, que talvez, pela distância social, não é alcançada pelos profissionais.

A Consciência Sanitária - Tal como já definida no contexto deste estudo e que se traduz não só na dimensão subjetiva mas no nível da prática, representou a nosso ver tema fundamental na análise empreendida.

Embora não tenhamos apresentado esta categoria de modo explícito, sua apreensão se deu a partir das falas concernentes às opiniões associadas a questões como o nível de informação relativo às recentes conquistas legais, a discussão da noção de saúde como um direito, além de juízos sobre o comportamento e a participação da população e seus condicionantes, entre outros aspectos.

$\mathrm{Na}$ opinião dos profissionais, tanto os das Unidades-Ensino quanto os das demais, a população em geral não tem nenhuma noção de cidadania. Segundo pudemos esclarecer, cidadania no entendimento destes profissionais é um conceito amplo que corresponde à "consciência dos direitos" e o "ser sujeito da história". Para eles, não é isso o que se observa na população:

- "Esta é uma população que perdeu toda noção do que é cidadania; não se sentem sujeitos dessa Unidade, não se sentem atores nessa história".

- “... como acham que pobre só tem direito àquilo mesmo, tem que conviver com aquilo... gostariam de melhorar... mas isto é um sonho distante..."

A esta ausência de uma consciência de que a saúde é um direito em permanente construção, os profissionais associam a relação desta população com os serviços. Em linhas gerais, corroboram a idéia de que a relação é de submissão; almejam o atendimento — a assistência nos moldes em que o Estado a oferece. No máximo, desejam ampliá-la, já que a vêem como uma dádiva, um favor:
- “É assim: uma população tão desapropriada

de tudo que qualquer coisa que funcione... é

um presente, uma dádiva que eles vão

agradecer o resto da vida".

Por outro lado, as opiniões também se encontram no fato de a relação da população com os serviços ser "pouco participativa". Entretanto, são absolutamente distintas as concepções de participação popular dos profissionais que atuam nas Unidades de Ensino, comparados aos demais. Para os primeiros, que valorizam muito a participação da população e tentam motivá-la:

- "Participar é participar de tudo... de discutir desde prioridades... o que fazer, como fazer, saber das dificuldades... até ajudar a destrinchá-las".

Nestes termos, para eles, "a participação popular não existe".

Indagados sobre os possíveis motivos para esta não-participação, este grupo aponta a crise de credibilidade, gerada inclusive pelo nãoatendimento de reivindicações anteriores, além do crescimento do narcotráfico associado à ausência de lideranças representativas:

\section{- "As pessoas vão se desestimulando aos poucos, quando elas vão fazendo as reivindicações e de repente não vêem os resultado".}

- "O crescimento do narcotráfico cria um medo nas pessoas, ela têm medo de participar, de votar ou de deixar de votar".

Como pudemos observar, a totalidade dos entrevistados das Unidades-Ensino atribui às condições de vida e à realidade social o fato de a população não participar.

Já o segmento que pertence às outras unidades possui uma visão inteiramente distinta, começando pelo que entendem por participação popular:

- "Tem coisas em que eu acho que a população deveria ajudar... Limpar o posto, né? Sei lá..." 
- "Tipo assim: precisa pintar o posto? Então o posto arruma as latas de tinta... Eles vêm e pintam o posto. Eu acho que aí seria a participação".

- "Eu acho que a população tem que estar no posto para dirigir, não... ela não deve vir aqui interferir nos mecanismos de trabalho do posto".

Temos assim uma visão instrumental de participação popular, onde o controle das ações e a divisão de poder não se incluem. Quanto ao fato de a população não participar, os profissionais destas unidades responsabilizam a própria população:

- "As pessoas não entendem a necessidade das coisas... a cultura deles é baixa". - “A população não está preparada para ter esse poder todo, eles misturam as estações, eles de repente se sentiriam poderosos demais".

Esta importante divisão acaba por se expressar na relação dos dois subgrupos com a população que atendem. Nas Unidades-Ensino, os profissionais respeitam o saber popular (sem confundi-lo com o saber técnico) e se colocam numa postura de troca com a população:

- "Eu tenho tentado uma postura de maior troca com os pacientes... eu não conheço nada do que eles me ensinam... então, estou ai pra aprender com eles..."

- "Eu não vim de fora para ensiná-los a se cuidarem mas para entender porque eles agem assim”.

Mas deixam claro que:

- “... esta postura não é dominante nas Unidades como um todo. Nem todos os profissionais se permitem, até por uma questão de defesa mesmo".

De fato, parece ser isto o que se passa nas Unidades Assistenciais aqui analisadas:

- "Lidar com eles é difícil porque o nível não ajuda".

- "Quanto mais baixo for o nível cultural, mais dificuldade você tem... porque as pessoas têm idéias que não tem nada a ver...

Têm crendices... não tem base médica".

Mas, apesar das distinções, ambos os grupos denotam uma clara separação técnico-usuário. Para eles, "técnico não é população" e por motivos distintos, vivem a angústia de não saberem trabalhar com os usuários. Os profissionais das Unidades-Assistênciais, pela "diferença de nível", os das Unidades-Ensino, pelo medo de "dirigir a população". $\mathrm{Na}$ fala de ambos os segmentos, há implícita uma concepção de certa forma "espontaneísta" da organização e tomada de consciência por parte da população, que se expressa reiteradamente na afirmação de que "eles (a população) precisam se organizar".

Entretanto, cabe registrar que no grupo das Unidades-Ensino (e só neste segmento) o papel do técnico neste processo é reconhecido, embora não se sintam desempenhando:

- "Eu acho que a gente silencia muito a população, não dá chance para ela se expressar".

- "Nossa formação profissional não nos dá condições para uma integração... tipo ... meu trabalho vai até aqui, não mais do que aqui ... isto perpetua uma relação que não viabiliza a participação popular”.

O Cotidiano da Prática Profissional Mesclando-se às opiniões sobre os aspectos que organizamos nos temas anteriores, emergiram informações importantes referentes ao lugar que os profissionais reservam para si próprios e para a população no espaço da assistência, bem como aos conflitos, desafios, ao lado das cargas e do sofrimento a que se expõem.

Analisamos estas informações, organizando-as em torno de um terceiro tema "O cotidiano da prática profissional", aqui considerado como um lugar estratégico para a compreensão da dimensão política, presente no espaço micro das práticas.

Indagados sobre o papel dos Serviços de Saúde na visão dos usuários, a totalidade dos profissionais entrevistados declarou que para os primeiros, os serviços são como "o médico", “o curandeiro", "o mágico" — um agente que pode proporcionar a cura. 
Nota-se, portanto, uma vinculação direta entre a concepção de saúde que, segundo os profissionais orienta a população, e o papel dos serviços. Sendo a saúde definida em termos de “reparação na máquina corporal”, este papel é repassado aos técnicos e aos serviços, não cabendo aos usuários outro lugar que o de "pacientes" neste processo. Em todas as Unidades há referências claras ao fato de que:

- “A relação da população com o posto é vinculada a tratamento, os pacientes nos procuram porque estão doentes, estão passando mal".

- "Eu acho que a população quer o mínimo, a população quer que o posto funcione, que tenha médico, que resolva o seu problema e acabou".

Nas Unidades-Ensino, os profissionais se ressentem bastante da ausência do que chamam de "conduta preventiva". Alguns poucos reconhecem que não há espaço para um atendimento mais amplo mas ainda assim, esperam da população uma busca dos serviços fora do que eles entendem por "doença" ou "emergência".

Conforme indagamos anteriormente e retomaremos mais adiante, cabe refletir sobre como a população pode ter uma "conduta preventiva", ou seja, buscar os serviços antes da "doença" se mesmo na emergência e na dor o atendimento é muitas vezes impossível. Este impasse estrutural, ao lado de outros condicionantes, como a própria concepção de saúde que orienta o grupo, parece ser um elemento decisivo na perpetuação desta postura.

Segundo os depoimentos, cabe ainda ressaltar que a ausência de uma "consciência sanitária" leva o usuário a "querer o mínimo" ou seja, identificar o direito à saúde como direito ao serviço, nos moldes em que lhe são oferecidos. Assim, a maioria das queixas e expectativas da população - segundo o relato dos profissionais — refere-se a questões diretamente vinculadas ao atendimento.

Dentre as queixas apontadas, destaca-se o atendimento demorado (tanto para o primeiro atendimento quanto a espera nas filas), seguido pela falta de remédios e de postos de emergência.

Segundo alegaram os profissionais de todas as Unidades, a população não suporta a negação. Argumentam a enorme dificuldade que encontram para buscar outros serviços mais distantes, dificuldades muito concretas para a população que, aliás, não compreende a distinção entre posto, hospital e emergência:

- "Aí eu compreendi que distância existe entre profissionais, planejadores e usuários. As lógicas são inteiramente diferentes. A gente aqui pensando que estava fazendo o melhor e a população com outra expectativa. Como a gente conversa pouco com eles!"

Esta breve passagem contém, pelo menos, três importantes indicações que serão aqui apenas referidas: a primeira dada pela distância entre a formação recebida e a realidade prática; a segunda pela distância, também existente entre planejadores e população; e a terceira referente à lacuna no diálogo profissional (e planejadores/usuários).

Deste modo, não é surpreendente que se verifique, como destaca Cohn et al. (1991: 11), que "o que é instituído como direito no nível institucional acaba sendo negado pela prática cotidiana da implementação das políticas de saúde".

Isto nos conduz a um outro aspecto presente no material analisado que corresponde ao papel que se reservam os técnicos no dia-a-dia dos serviços.

Mais uma vez verificamos uma clara distinção entre as Unidades-Ensino e as demais. Os profissionais das Unidades-Ensino reconhecem a necessidade da busca de novas estratégias de ação para avançar na garantia do direito à saúde. Idealizam uma prática diferente da que desenvolvem embora reconheçam que o dia-adia quase impossibilita o repensar desta prática. A prática idealizada supõe um fazer que supere a questão técnica, embora tenham que lidar com o fato de "a população querer o que é técnico" e o crescente "sucateamento do público" que lhes impõe condições de trabalho muito adversas:

\footnotetext{
- "O pessoal de Saúde fica entre a população

e os interesses estatais... muita coisa é colocada teoricamente mas a realidade é outra".
} 
- "A Unidade não conseguiu pensar uma estratégia de participação popular... na verdade, embora a gente tenha esta discussão há muito tempo, a gente não conseguiu forjar um mecanismo concreto que estimulasse essa participação".

- "Eu atribuo à falta de tempo... estar no posto significa responder a tanta demanda de febre, dor de barriga, hipertensão... isto é tão volumoso, é tão gigantesco, que o resto fica na teoria".

Como resultado disto, segundo apontam:

- “Tanto a população nos busca... quanto nós profissionais de saúde acabamos respondendo de maneira imediata".

E o que julgam mais grave:

- “... os profissionais de saúde, em cima do discurso de que este governo não é sério, acabam se descomprometendo individualmente com o trabalho do dia-a-dia... e acabam também perdendo o crédito com a população".

No que se refere às Unidades Assistenciais, nota-se uma valorização do fazer técnico, sendo as dificuldades desta prática o principal problema. Coerentemente com o modelo biomédico que neste grupo se impõe com muito mais força, vê-se claras alusões ao que ele preconiza:

- "Toda vez que o pessoal vem aqui eu fico lembrando a necessidade de tomar remédio... digo que precisa tomar remédio. Explico o porquê da coisa”.

- “A função de um Centro de Saúde é puramente isto: atendimento médico".

Embora não tenha sido este o nosso objeto, cabe registrar a abundância de depoimentos ratificando a importância das cargas psíquicas. Uma importante carga psíquica que aparece nos relatos é o medo (Brito \& Porto, 1991; Dejours, 1987). O crescimento assustador da violência urbana e do narcotráfico não só deixa suas marcas na população, limitando, como vimos, sua liberdade e seu bem-estar, mas também se colocam como um elemento de risco muito concreto para os profissionais que lidam com a população:
- “... esta questão do narcotráfico dificulta em

muito o trabalho do serviço de saúde, não só

do serviço, mas do trabalho integrado à comunidade".

- "...se as pessoas têm medo mesmo e cada um quer ficar na sua para não correr risco... então como é que se vai promover participação popular?”

Mas não é só no sentimento de medo que se nota a intensidade das cargas psíquicas; estas também se revelam sob forma de sentimentos de insatisfação/frustração. Dentre os determinantes deste estado emocional, destacaremos apenas dois que pela recorrência e dramaticidade dos relatos não poderiam ser aqui ocultados.

Um primeiro elemento que nos pareceu mais contundente, percebido pelos profissionais como uma violência não só a eles próprios mas à própria população, diz respeito ao crescimento da demanda ao lado do sucateamento do setor público. A impossibilidade de atender as pessoas que acorrem às Unidades e Centros de Saúde se desdobra em muitos problemas:

- “... tem um nível de reclamação muito grande... que a demanda é muito grande, que as pessoas estão muito doentes, enfim, é muito estressante esse dia-a-dia".

- "Era uma guerra feia, distribuir aqueles números... se você oferecer vinte números, vai ter quarenta na fila... se oferecer quarenta, terá sessenta..."

- "Você chega inteiro sai despedaçado, entendeu?"

Espremidos entre uma população que não dispõe de recursos e um Estado completamente inoperante no que tange a garantir o "direito à saúde" estes profissionais vivem violentas contradições: melhorar a qualidade do atendimento X explosão da demanda: estabelecer um vínculo com a população $\mathrm{X}$ ter que dizer não; oferecer um atendimento de boa qualidade $\mathrm{X}$ a falta total de infra-estrutura. Isto nos conduz ao "clima emocional" que nos pareceu típico do grupo estudado — uma mescla de desânimo e impotência:

- "Ultimamente tem dado muita sensação de impotência... impotência e desânimo". 
- "Aquela coisa de malhar com o ferro frio. Você há dez anos falando as mesmas coisas para as mesmas pessoas e você não vê um resultado concreto".

- "Eu optei por fazer Saúde Pública, para fazer um outro tipo de trabalho, ai a gente vai se deparando com a realidade".

Assim, no que se refere às cargas e ao sofrimento, os profissionais, tanto os das Unidades Ensino quanto os das Unidades Assistenciais, convergem para os sentimentos que acabamos de explicitar. Cabe, entretanto, assinalar a diferença em termos de níveis de intensidade, sendo este sentimento mais forte nos profissionais das Unidades-Ensino, segundo observamos. Estes profissionais, pelo fato de se colocarem como objeto de trabalho "problemas que não são só técnicos”, se defrontam a todo instante com problemas que pertencem a esferas mais amplas nas quais o papel (técnico) do profissional perde força. A dificuldade de obter resultados palpáveis e a preocupação mais nítida com o agravamento da situação sanitária no país, são fontes de uma grande ansiedade e desânimo para este segmento, mais do que para o outro.

Apesar disto, os grupos prosseguem. Mas como e para onde caminham? Será que vêem alguma saída?

A Transformação do Quadro Atual Neste percurso que foi desde a questão da Saúde, passando pelos Direitos, pelas conquistas e pela situação de saúde no país, passando pelo cotidiano do trabalho num locus do setor, tocamos inevitavelmente na questão das perspectivas e estratégias de construção dos direitos sociais - em outras palavras - na transformação do quadro atual, do ponto de vista dos profissionais que aí atuam.

Aqui, de novo, é interessante notar as diferenças nos pontos de vista dos segmentos entrevistados. Os profissionais das Unidades Assistenciais demonstraram uma maior hesitação ao emitirem suas opiniões, remeteram para uma ação intersetorial (Educação, Meio Ambiente etc.) a superação do quadro, mas, cabe frisar, em nenhum momento se colocaram como sujeitos das ações:

- "Eu não sei como melhorar... eu acho que... tem que investir na cultura desse país. As pessoas tem que saber ler... Enquanto isto não acontecer, vai ficar este abismo..."

- "Tem que ter saneamento e educação".

- "Para mudar a situação, a população teria que reivindicar as coisas, né?"

Quanto às Unidades-Ensino, seus profissionais demonstraram uma certa "intimidade de reflexão" com a questão, reconhecendo a grande maioria, a natureza política da questão:

- “No meu ponto de vista esta questão é política... a comunidade não está carecendo de saber se a Constituição garante ou não, essa comunidade está carecendo de saber de que forma faz esta Constituição funcionar".

Além disto, apesar de constatarem a desinformação da população e a importância da informação no processo de construção dos direitos, julgam que a transformação transcende o conhecimento racional e "passa pela mobilização emocional”. E indicam que:

\section{- "Mesmo as lideranças políticas que compreendem o direito à cidadania, conhecem o SUS, o SUDS, não se diferenciam do resto da população na relação com o serviço de saúde". \\ - "O que a gente já passou de informação e a população não faz nada...” \\ - "Isto está tão introjetado que carece de muitos anos... de um trabalho de resgate... mas não é um repensar teórico, só um... um repensar teórico; é um repensar de vivência mesmo".}

Ainda assim, se colocam claramente como atores neste processo, quando discutem o trabalho neste nível. Na opinião do grupo há necessidade de um espaço de reflexão conjunta, espaço que é entendido como um espaço político no qual situam a relação profissionais/usuários. Identificam, mais uma vez, a crise de credibilidade, uma crise que é ética, e o fracasso das iniciativas populares como importantes fatores na apatia atual. Mas, apesar de tudo, se sentem sujeitos, nesta história. E levantam questões que deixamos aqui para reflexão: 
- "Para além do técnico, eu acho que a gente precisa montar uma estratégia de repensar.. a gente tem ainda o discurso do dono do saber, a gente não sabe ouvir... E aí, a gente tem um monte de desculpas: a demanda é muito grande, são os nossos limites, e a gente continua reproduzindo..."

- "A gente tem que tentar constuir espaços para que isto (a construção dos direitos) possa acontecer, é o que me mantém trabalhando no setor público, senão já tinha largado".

\section{CONCLUSÃO}

Ao longo desta investigação, mais uma vez constatamos no nosso país, a falta de correspondência entre os direitos assegurados nos discursos oficiais e a realidade concreta a que se referem. No caso específico do setor saúde, o caminho a ser percorrido até que se conquiste a eqüidade parece ser longo. O que se observa hoje na realidade dos serviços públicos está muito distante da tão almejada garantia do direito à saúde.

Por outro lado, cabe considerar em qualquer estratégia de mudança deste quadro a heterogeneidade presente nos profissionais e nos serviços, o que, conforme procuramos demonstrar, desautoriza generalizações. Lidar de modo conseqüente com "Unidades de Saúde", "Rede de Serviços" e "Profissionais de Saúde" colocanos frente à urgência de desvendar diversos aspectos de natureza qualitativa, dimensão tão pouco considerada até aqui nos Planos e Programas do Setor.

Por último, cabe ressaltar a importância central dos paradigmas que orientam as práticas em saúde, destacando a necessidade de uma re orientação da formação dos profissionais que atuam nesta área se quisermos contribuir efetivamente para a transformação do atual modelo de assistência.

\section{AGRADECIMENTOS}

A autora agradece a Kátia de Carvalho Affonso (sanitarista e professora do Nesc/ UFRJ) pela participação efetiva no desenvol- vimento deste estudo, sem o que não teria sido possível realizá-lo, bem como pelas importantes contribuições dadas ao texto.

Um agradecimento especial à antropóloga Rosa Maria Magalhães de Oliveira pelo auxílio valioso na realização das entrevistas e, em particular, à direção e aos profissionais e usuários das instituições participantes pelos depoimentos que nos confiaram.

\section{RESUMO}

BOSI, M. L. M. Cidadania, Participação Popular e Saúde na Visão dos Profissionais do Setor: Um Estudo de Caso na Rede Pública de Serviços. Cad. Saúde Públ., Rio de Janeiro, 10 (4): 446-456, out/dez, 1994.

Este trabalho aborda a questão da cidadania e da participação popular em Saúde, a partir da análise das concepções de um grupo específico: profissionais de Saúde que atuam nas Unidades de Cuidados Básicos da Área Programática 3.1 do Município do Rio de Janeiro (Brasil).

Busca-se analisar suas representações referentes ao tema em estudo, confrontando-as com as que orientam o texto constitucional no capítulo referente à Saúde, ao mesmo tempo em que se discute o papel dos técnicos em sua relação com os usuários, no processo de construção de uma "Consciência Sanitária”. As informações recolhidas através de trabalho de campo conduzido a partir de metodologia qualitativa de pesquisa social, indicam uma heterogeneidade marcante nas concepções dos profissionais, o que os dividem em dois segmentos: aqueles pertencentes às "Unidades-Ensino" e os que atuam nas "Unidades-Assistenciais".

A análise aponta, ainda, para o papel estratégico desempenhado pelas relações cotidianas no processo de mudança social e construção dos direitos ao mesmo tempo em que discute a viabilidade deste processo frente ao desvendamento da subjetividade dos agentes que lhe dão vida.

Palavras-Chave: Profissionais de Saúde; Sistema de Saúde; Cidadania; Participação Popular 


\section{REFERÊNCIAS BIBLIOGRÁFICAS}

BERLINGUER, G., 1978. Medicina e Política. São Paulo: Hucitec.

BOBBIO, N., 1992. A Era dos Direitos. Rio de Janeiro: Campus.

BRITO, J. C. \& PORTO, M. F. S., 1991. Processo de Trabalho. Riscos e Cargas à Saúde. Rio de Janeiro: Cesteh/Ensp/Fiocruz. (Mimeo.)

CAPRA, F., 1986. O Ponto de Mutação. São Paulo: Cultrix.

CARVALHO, R. M., 1991. Modelos Assistenciais de Unidades Básicas de Saúde e Integralidade. Tese de Mestrado, Rio de Janeiro: Escola Nacional de Saúde Pública, Fundação Oswaldo Cruz.
COHN, A.; NUNES, E.; JACOBI, P. \& KARSCH, U. S., 1991. A Saúde Como Direito e como Serviço. São Paulo: Cortez.

DEJOURS, C., 1987. A Loucura do Trabalho. São Paulo: Oboré Editorial.

MICHELAT, G., 1975. Quelque contribuitions à la methodologie de l'entretien non-directif d'enquête. Révue Française de Sociologie, XVI: 229-247.

MINAYO, M. C. S., 1992. O Desafio do Conhecimento. Pesquisa Qualitativa em Saúde. São Paulo: Hucitec/Rio de Janeiro: Abrasco.

THIOLlENT, M., 1987. Crítica Metodológica, Investigação Social Enquete Operária. $5^{\mathrm{a}}$ ed., São Paulo: Polis. 